The growing interest in neuroendocrine tumours is due to the dynamic growth of detection of this type of cancer. Neuroendocrine tumours (neuroendocrine neoplasms - NENs / neuroendocrine tumours - NETs) derive from glands, groups of endocrine cells and diffuse neuroendocrine system cells. Mainly they derive from the gastrointestinal tract (gastroenteropancreatic-neuroendocrine tumours - GEP-NETs). Currently the modified WHO classification from 2010 is widely used. An important element in the choice of treatment is histological maturity based on mitotic activity and on assessment of proliferation activity (Ki-67). The treatment of choice is surgery. In most cases, complete surgical removal is impossible because of the advanced staging at the time of diagnosis. In well-differentiated neoplasms where the expression of somatostatin receptors is expected, patients are qualified for somatostatin analogues therapy. Poorly differentiated lesions are qualified for chemotherapy. In the guidelines of ENETS (European Neuroendocrine Tumor Society) from 2007 the rules concerning monitoring depending on the WHO classification were specified.

Key words: neuroendocrine tumours of the gastrointestinal tract and pancreas, therapy, follow-up.

\section{Contemporary methods of therapy and follow-up of neuroendocrine tumours of the gastrointestinal tract and the pancreas}

\author{
Paweł Gut ${ }^{1}$, Jakub Fischbach ${ }^{1}$, Grzegorz Kamiński $^{2}$, Marek Ruchała ${ }^{1}$
}

1Department of Endocrinology and Metabolism, Poznan University of Medical Sciences, Poznan, Poland

2Department of Endocrinology and Isotope Therapy, CSK MON, Military Institute of Medicine, Warsaw, Poland

\section{Introduction}

The growing interest in neuroendocrine tumours is due mainly to the dynamic growth of detection of this type of cancer in recent decades. According to their specific nature, they are of interest to several medical specializations and require cooperation between surgeons, oncologists, endocrinologists and nuclear physicians. The disparate nature of this type of cancer often necessitates a variety of approaches to both treatment and follow-up of patients with this disease. Neuroendocrine neoplasms (tumours) (neuroendocrine neoplasms - NENs/ neuroendocrine tumours - NETs) derive from glands, groups of endocrine cells and diffuse neuroendocrine system cells (DES) [1]. In $66 \%$ of cases neuroendocrine tumours derive from the gastrointestinal tract (gastroenteropancreatic - GEP, gastrointestinal neuroendocrine tumours - GI-NETs). In the widest currently available epidemiological studies the prevalence reaches 5-8 cases per 100000 population [2]. Since the introduction of the definition "carcinoid" by Oberndorfer, neuroendocrine neoplasms developing in the digestive tract have commonly been named by this term. The turning point occurred in 2000 when a group of European pathologists introduced a classification under the auspices of the World Health Organization (WHO) which specified the names of these tumours. Currently the modified classification from 2010 is widely used:

- neuroendocrine tumour grade 1 (NET G1),

- neuroendocrine tumour grade 2 (NET G2),

- neuroendocrine cancer, small and large cell type grade 3 (NEC),

- mixed adenoneuroendocrine cancer (MANEC),

- hyperplastic and preneoplastic lesions.

An important element of consideration in the choice of treatment is histological maturity based on mitotic activity of cells in preparations stained with eosin-haematoxylin and assessment of proliferation activity of cells based on immunohistochemical reaction with MIB-1 antibody (anti-Ki-67) [3]. The criteria for histological assessment of maturity are shown in Table 1.

An equally important factor determining the choice of treatment is the clinical stage of disease. In clinical stages I-III there might be possibilities of a cure. In stage IV where we have advanced cancer, only palliative treatment to improve the quality of life can be considered. The treatment of choice is surgery. In most cases, complete surgical removal of the lesion is impossible because of the advanced staging at the time of diagnosis. In the case of a well-differentiated neoplasm with a low proliferative index Ki-67 where the expression of somatostatin receptors (somatostatin receptor scintigraphy) is expected, patients might be qualified for treatment with somatostatin analogues. Poor- 
Table 1. The criteria for histological assessment of maturity

\begin{tabular}{ccc} 
Grading & Mitotic activity & $\begin{array}{c}\text { Proliferative activity } \\
(\text { Ki-67) }\end{array}$ \\
\hline G1 & $<2$ & $\leq 2$ \\
G2 & $2-20$ & $3-20$ \\
G3 & $>20$ & $>20$
\end{tabular}

ly differentiated lesions with a high proliferative index (weak or negligible expression of somatostatin receptors) are qualified for chemotherapy $[5,6]$.

\section{Methods of therapy}

\section{Somatostatin analogues}

Somatostatin analogues (SA) are now considered as a "gold standard" for the treatment of NETs [6]. These drugs not only reduce the secretion of biologically active substances by abolishing symptoms but also affect the inhibition of disease progression [7]. Therapy with these substances makes use of the fact that about $80 \%$ of NETs and their metastases have SSTR2 receptor expression [6, 8, 9]. In clinical practice there are two analogues used: octreotide and lanreotide. They exhibit high affinity for human somatostatin receptors (SRS), type 2 and $5[10,11]$. Treatment with long acting SA is as effective at suppressing symptoms and tumour progression as short-acting forms that are still used for rapid control of symptoms of functioning NETs $[12,13]$. In vitro and in vivo studies have demonstrated the antiproliferative activity of SA, which may involve direct effects on receptors present on tumour cell membranes, and indirect effects, through inhibition of growth factors and hormones, formation of metastasis, angiogenesis inhibition, induction of apoptosis and effects on lymphocyte proliferation and immunoglobulin synthesis $[14,15]$. In 5\% of cases of NET reduction in size, and in $40-80 \%$ of cases stabilization of tumour growth are observed during SA therapy $[12,16,17]$. Therapy is persistent and associated with administration of Sandostatin LAR $30 \mathrm{mg}$ every 28 days or Somatuline Autogel at doses of 60-120 mg every $28-56$ days. These drugs are generally well tolerated and the side effects reported by patients include periodic diarrhoea and abdominal pain, which are often transient. Other side effects are impaired glucose tolerance, and rarely cholelithiasis (in 20-50\% of patients) [16].

\section{Isotope treatment of neuroendocrine tumours}

In this case, a somatostatin analogue is connected to a radionuclide that is a beta emitter, destroying the cell's DNA structure. Currently the most widely used emitters of ionizing radiation are yttrium (90Y) and lutetium (177Lu) particles [1823]. In the biggest published study, 90 patients with GEP-NETs were treated with three cycles of radiopharmaceutical (90Y) with activity of a single dose of $4.4 \mathrm{GBq}$; in no case was complete remission observed, while PR was achieved in $4 \%$ of cases and SD in $70 \%$. The median progression-free survival was 16.3 months [24]. These results are comparable to the second largest multicenter phase I study evaluating the therapeutic effect of 9OY-DOTATOC [23]. In clinical use there is also a 90Y-labelled somatostatin analogue [DOTAO, Tyr3] octreotate (DOTATATE), where the C-terminal amino acid threonine is replaced by its alcohol derivative. Changing of the molecular structure has resulted in several times increased susceptibility to the somatostatin receptor 2 (SSTR2) in comparison to DOTATOC [24]. In the preliminary results of the studies using this radiopharmaceutical in GEP-NETs expressing somatostatin receptors, PR was achieved in 37\% and SD in $70 \%$ of cases.

The first reports of therapy with use of 177Lu-DOTATATE showed promising results: $30 \%$ complete (CR) and partial $(P R)$ response, and stable disease (SD) in $40 \%$ of cases [25]. These results were confirmed in subsequent studies involving 310 patients with GEP-NET treated with the same substance [26]. Isotope therapy using somatostatin analogues labelled with radioactive isotopes is a promising form of treatment, especially for patients disqualified from surgery and who have demonstrated the existence of somatostatin receptors on the surface of the tumour in receptor scintigraphy. Because of the potentially harmful effect of isotope therapy on renal function, preparations of amino acid mixtures (lysine-arginine) are used, which reduce the absorption of radionuclide [22]. Risk factors that may affect kidney function after radionuclide therapy are the radiation dose used in the various cycles of therapy and cumulative doses of the isotope, patient age and comorbidities such as diabetes and hypertension [27]. Disorders in bone marrow functioning, which, however, are mostly mild and transient, are also observed.

\section{Therapy with ${ }^{131} \mathrm{l}$-meta-iodobenzyl guanidine}

Aside from using ${ }^{131}$-meta-iodobenzyl guanidine (MIBG) scintigraphy in the diagnosis and staging of GEP-NETs, it can be used to select patients likely to benefit from therapy with ${ }^{131}$ I-MIBG. Visualization of the neoplastic process in scintigraphy is a prerequisite for qualification for this type of therapy. The treatment is carried out for 5 cycles every 3-6 months with 7.4-11.2 GBq doses. Results of studies on use of ${ }^{131}$ I-MIBG in cases of metastatic disease indicate a $13-15 \%$ objective tumour response to therapy. Biochemical response defined as $>50 \%$ reduction in the concentration of chromogranin A (CgA) and 5-hydroxyindoleacetic acid (5-HIAA) was estimated at $37-46 \%[28,29]$, but objective tumour response to treatment was estimated at 13-35\% [28-30]. Treatment is generally well tolerated, and side effects are similar to those radiopharmaceuticals mentioned above. Therapy using MIBG can be an alternative means of treatment in case of visualization of neoplastic foci in MIBG scintigraphy with no uptake in somatostatin analogue receptor scintigraphy. In patients with an active thyroid gland it is necessary to use liquid iodine or sodium perchlorate to block the uptake of MIBG unbound free iodine.

\section{Chemotherapy}

The value of the widely used cytotoxic agents in oncology in cases of neuroendocrine tumours is limited, as evidenced by low rates of objective response and short duration of remission. Combined cytotoxic therapy shows greater efficacy compared to monotherapy. The therapeutic scheme evaluated most often in well-differentiated 
neuroendocrine tumours was an association of streptozotocin with doxorubicin and/or fluorouracil. Objective responses are higher (estimated at 30-60\%) and longer (10-36 months) compared with the results of monotherapy. The use of multidrug therapy is associated with more frequent and more severe side effects, concerning in particular the combination streptozocin and doxorubicin. In advanced, poorly differentiated NETs platinum derivatives are used. Objective responses were observed in $42-80 \%$ of cases when the combination of cisplatin and etoposide was used [31-33] and in 78\% of cases with use of oxaliplatin [34]. However, despite the satisfactory results of the treatment response rate, median survival time is between 8 and 11 months [33]. Currently there are considerable difficulties with chemotherapy with streptozotocin due to the limited availability of the drug.

\section{mTOR inhibitors}

In two studies carried out recently with the participation of patients with neuroendocrine tumours of the pancreas, there was a promising result of antitumor activity of everolimus (Afinitor) $[35,36]$. It inhibits the mammalian target of rapamycin (mTOR), a serine-threonine kinase that stimulates cell growth, proliferation and angiogenesis [35-37]. Autocrine activation of the mTOR signal pathway taking place via the insulin-like growth factor 1 participates in cell proliferation of neuroendocrine pancreatic tumours [38]. In a prospective randomized phase III study using everolimus in 410 patients with advanced low- and middle-grade pancreatic neuroendocrine tumours, significant prolongation of progression-free survival of the disease in the everolimus group compared to placebo was observed [39]. Adverse events were mostly mild, with inflammation of the oral mucosa, rash and diarrhoea most often reported. This drug is registered in Poland for the treatment of unresectable well-differentiated pancreatic neuroendocrine tumours. Research is ongoing to evaluate the efficacy of everolimus in neuroendocrine gastrointestinal tract and lung tumours.

\section{Other medications}

Neuroendocrine tumours are characterized by extensive vascularization and high expression of vascular growth factors (VEGF). There are reports of a strong correlation of VEGF expression and tumour size and the ability of tumour metastasis [40]. Currently, there are a number of antiangiogenic agents being evaluated in clinical trials. These include human monoclonal antibody against VEGF (bevacizumab), tyrosine kinase inhibitors (sunitinib, sorafenib, vatalanib, imatinib) and other factors affecting the proliferation of blood vessels, such as thalidomide and endostatins. Among the published results of clinical trials of these drugs, sunitinib has the most promising efficacy. However, this applies only to inoperable pancreatic neuroendocrine tumours. In Poland, none of these preparations have been approved yet for the treatment of GEP-NETs.

\section{Monitoring of treatment}

According to the guidelines of ENETS from 2007 [41], the rules concerning monitoring of neuroendocrine tumours, depending on the classification of both the WHO and the TNM and clinical course, were specified.

\section{Endocrine tumours of the stomach}

Gastric tumours were divided into five categories:

- benign tumours - benign gastric tumours possible to be removed endoscopically ( $T 1$, size less than $1 \mathrm{~cm}$ ),

- resectable tumours, probably benign $-\mathrm{T}_{2} \mathrm{~N}_{0} \mathrm{M}_{0}$ tumours, larger than $1 \mathrm{~cm}$, infiltrating the muscle membrane and submucosa,

- resectable malignant tumours with or without involvement of lymph nodes; this category includes tumours with Ki-67 above 2\% (G2 and G3), T2, T3,

- unresectable gastric tumours with or without involvement of lymph nodes and metastases or without metastases G1-G3.

In the case of type 1 (gastritis type A - easily removed endoscopically) monitoring by examination with gastroscopy should be carried out at yearly intervals. Determination of concentrations of gastrin and chromogranin A (CgA) is in this case without clinical relevance. In cases of resective, potentially benign type 2 lesions, the recommended way of monitoring is imaging studies (ultrasound, CT, MRI) after 6 months, followed by repeat testing on an annual basis. Scintigraphy is recommended at the beginning of the disease's detection, then every 2 years. Chromogranin A test should be repeated every 6 months. In the case of type 3 neoplasms, stage G2-G3 imaging studies (ultrasound, CT, MRI) should be repeated every 3 months. In the case of potentially unresectable or diffuse tumours local resection should always be considered as a cytoreductive treatment. Recommendations for monitoring are the same as described above, according to the histopathological evaluation of G1 and G2-G3.

\section{Endocrine tumours of the small intestine}

In assessing the progress and effectiveness of treatment of neuroendocrine tumours of the jejunum and ileum secreting serotonin (carcinoid) it is helpful to determine CgA and 5-HIAA concentration. In patients treated with somatostatin analogues a decrease in urinary 5-HIAA and blood CgA levels coexists with a reduction in the intensity and frequency of clinical symptoms (flush, diarrhoea). There is good agreement $(80 \%)$ between the change in tumour size and the change in CgA levels. Even greater compliance (88\%) was found in patients with non-functioning tumours, where it is not possible to use another marker [42-44]. Imaging studies (ultrasound, CT) should be carried out every 6 months. In patients with carcinoid heart syndrome echocardiography also should be repeated every 6 months. In case of progressive disease control imaging and biochemical studies should be performed every 3 months [45-47]. Monitoring of patients with GEP/NET of the small intestine should be for life. Epidemiological data indicate that 25 years after diagnosis, only $25 \%$ met the criteria for cure [48].

\section{Endocrine tumours of the appendix}

In assessing the progress and effectiveness of treatment of patients with NET of the appendix it may be useful to mark 
CgA and 5-HIAA [46], although the authors of the ENETS recommendations from 2009 stated that markers should be measured in case of positive imaging studies [43]. In the case of non-metastatic NET of the appendix with a diameter of less than $2 \mathrm{~cm}(T 1, T 2)$, considered as cured after resection of appendicitis or hemicolectomy, the determination of CgA concentration should be done once 6-12 months later. In the case of functioning tumour the determination of urinal 5-HIAA concentration should be performed. In addition, all patients after surgery should have imaging studies (ultrasound, CT, MRI) performed after 6 and 12 months. Somatostatin receptor scintigraphy should be performed every 2 years for $\mathrm{G} 1$ tumours, and every year in the case of G2 and G3 tumours [49].

\section{Neuroendocrine tumours of the colon}

After endoscopic or surgical treatment of lesions with size up to $1 \mathrm{~cm}$, without lymph node metastases, monitoring of patients is not recommended. If tumours exceed $2 \mathrm{~cm}$, control tests should always be planned, even if the surgery was radical. For tumours measuring $1-2 \mathrm{~cm}$ a control test should be proposed in case of high-risk features (presence of angioinvasion, infiltration of the proper muscle membrane, high mitotic index) [50]. The monitoring methods are colonoscopy, CT, MRI and CgA [51].

In patients with high risk positive markers, research should be carried out every 4-6 months in the first year, and then every year for 10 years, and in patients without markers of high risk, once a year for 10 years [52].

\section{Pancreatic neuroendocrine tumours}

Monitoring of treatment includes clinical examination as well as biochemical and radiological assessment and it should be tailored to the severity of the disease, to demonstrate the results of surgical treatment and also to reveal indications for additional therapy. Cases of well-differentiated pancreatic endocrine tumours should have a control test carried out every 6-12 months (endoscopic ultrasound, CT, MRI, insulin, gastrin, (gA). Somatostatin receptor scintigraphy or PET-Ga68 should be performed 6 months after surgery. In patients with poorly differentiated tumours, imaging studies should be performed every $2-3$ months $[53,54]$.

The authors declare no conflict of interest.

\section{References}

1. Plöckinger U, Rindi G, Arnold R, et al. Guidelines for the diagnosis and treatment of neuroendocrine gastrointestinal tumours. A consensus statement on behalf of the European Neuroendocrine Tumour Society (ENETS). Neuroendocrinology 2004; 80: 394-424

2. Siddique ZL, Gustaffson BI, Hauso O, et al. The epidemiology of neuroendocrine tumors. In: Nordic and North American Neuroendocrine Tumor Management: a clinical and scientific synopsis 2008. Modlin IM, Oberg KE (eds.). Leopard Communication AB, Stockholm 2008; 170-5.

3. Rindi G, Klöppel G, Alhman H, et al. TNM staging of foregut (neuro)endocrine tumours: a consensus propos including a trading system. Virchows Arch 2006; 449: 395-401.
4. Kos-Kudła B, Bolanowski M, Handkiewicz-Junak D i wsp. Zalecenia diagnostyczno-lecznicze w guzach neuroendokrynnych układu pokarmowego (rekomendowane przez Polską Sieć Guzów Neuroendokrynnych). Endokrynol Pol 2008; 59: 41-56.

5. Oberg K, Kvols L, Caplin M, et al. Consensus report on the use of somatostatin analogs for the management of neuroendocrine tumors of the gastroenteropancreatic system. Ann Oncol 2004; 15: 966-73.

6. Oberg K. Chemotherapy and biotherapy in the treatment of neuroendocrine tumors. Ann Oncol 2001; 12 Suppl 2: S111-4.

7. Arnold R, Simon B, Wied M. Treatment of neuroendocrine GEP tumors with somatostatin analogs. Digestion 2000; 62 Suppl 1: 84-91.

8. Maini CL, Sciuto R, Festa A, et al. The role of nuclear medicine in GEP-NET diagnosis and therapy. In: Update in neuroendocrinology. Baldelli R, Casanueva FF, Tamburrano G (eds.). Udine Centro UD 2004; 529-44.

9. Oberg K. Carcinoid tumors: molecular genetics, tumor biology, and update of diagnosis and treatment. Curr Opin Oncol 2002; 14: 38-45.

10. Patel YC, Srikant CB. Subtype selectivity of peptide analogues for all five cloned human somatostatin receptors (hSSTR1-5). Endocrinology 1994; 135: 2814-7.

11. Patel YC. Molecular pharmacology of somatostatin receptor subtypes. J Endocrinol Invest 1997; 20: 348-67.

12. Delaunoit T, Rubin J, Neczyporenko F, Erlichman C, Hobday TJ. Somatostatin analogues in the treatment of gastroenteropancreatic neuroendocrine tumors. Mayo Clin Proc 2005; 80: 502-6.

13. Dogliotti L, Tampellini M, Stivanello M, Gorzegno G, Fabiani L. The clinical management of neuroendocrine tumors with long-acting repeatable (LAR) octreotide: comparison with standard subcutaneous octreotide therapy. Ann Oncol 2001; 12 Suppl 2: S105-9.

14. Bousquet C, Puente E, Buscail L, Vaysse N, Susini C. Antiproliferative effect of somatostatin analogs. Chemotherapy 2001; 47 Suppl 2: 30-9.

15. van Hagen PM, Krenning EP, Kwekkeboom DJ, Reubi JC, Anker-Lugtenburg PJ, Löwenberg B, Lamberts SW. Somatostatin and the immune and haematopoetic system: a review. Eur J Clin Invest 1994; 24: 91-9.

16. Panzuto F, Nansoni S, Corleto VD, et al. Pharmacological treatment of gastroenteropancreatic neuroendocrine tumors. In: Baldelli R, Casanueva FF, Tamburrano G (eds.). Update in neuroendocrinology. Udine Centro UD 2004; 547-61.

17. Shojamanesh H, Gibril F, Louie A, Ojeaburu JV, Bashir S, Abou-Saif A, Jensen RT. Prospective study of the antitumor efficacy of longterm octreotide treatment in patients with progressive metastatic gastrinoma. Cancer 2002; 94: 331-43.

18. Otte A, Herrmann R, Heppeler A, Behe M, Jermann E, Powell P, Maecke HR, Muller J. Yttrium-90 DOTATOC: first clinical results. Eur J Nucl Med 1999; 26: 1439-47.

19. Waldherr C, Pless M, Maecke HR, Haldemann A, Mueller-Brand J. The clinical value of [90Y-DOTA]-D-Phe1-Tyr3-octreotide (90YDOTATOC) in the treatment of neuroendocrine tumors: a clinical phase II study. Ann Oncol 2001; 12: 941-5.

20. Waldherr C, Pless M, Maecke HR, Schumacher T, Crazzolara A, Nitzsche EU, Haldemann A, Mueller-Brand J. Tumor response and clinical benefit in neuroendocrine tumors after 7.4 GBq 90-YDOTATOC. I Nucl Med 2002; 43: 610-6.

21. Waldeherr C, Schumacher T, Maecke HR, et al. Does tumor response depend on the number of treatment sessions at constant injected dose using 90-Yttrium-DOTATOC in neuroendocrine tumors? Eur J Nucl Med 2002; 29: S100 (abstract).

22. Bodei L, Cremonesi M, Zoboli S, et al. Receptor-mediated radionuclide therapy with 90Y-DOTATOC in association with amino acid infusion: a phase I study. Eur J Nucl Med Mol Imaging 2003; 30: 207-16.

23. Valkema R, Pauwels S, Kvols LK, et al. Survival and response after peptide receptor radionuclide therapy with [90Y-DOTA0,Tyr3]octreotide in patients with advanced gastroenteropancreatic neuroendocrine tumors. Semin Nucl Med 2006; 36: 147-56.

24. Reubi JC, Schär JC, Waser B, Wenger S, Heppeler A, Schmitt JS, Mäcke HR. Affinity profiles for human somatostatin receptor subtypes SST1SST5 of somatostatin radiotracers selected for scintigraphic and radiotherapeutic use. Eur I Nucl Med 2000; 27: 273-82. 
25. Kwekkeboom DJ, Bakker WH, Kam BL, et al. Treatment of patients with gastro-entero-pancreatic (GEP) tumours with the novel radiolabelled somatostatin analogue [(177)Lu-DOTA(0),Tyr(3)]octerotate. Eur J Nucl Med Mol Imaging 2003; 30: 417-22.

26. Kwekkeboom DJ, de Herder WW, Kam BL, et al. Treatment with the radiolabeled somatostatin analog [177Lu-DOTA0,Tyr3]octreotate: toxicity, efficacy and survival. J Clin Oncol 2008; 26: 2124-30.

27. Bodei L, Cremonesi M, Ferrari M, et al. Long-term evaluation of renal toxicity after peptide receptor radionuclide therapy with $90 \mathrm{Y}$ DOTATOC and 177Lu-DOTATATE: the role of associated risk factors. Eur J Nucl Med Mol Imaging 2008; 35: 1847-56.

28. Bomanji JB, Wong W, Gaze MN, Cassoni A, Waddington W, Solano J, Ell PJ. Treatment of neuroendocrine tumors In adults with 123I-MIBC therapy. Clin Oncol (R Coll Radiol) 2003; 15: 193-8.

29. Safford SD, Coleman RE, Gockerman JP, Moore J, Feldman J, Onaitis MW, Tyler DS, Olson JA Jr. lodine-131 metaiodobenzylguanidine treatment for metastatic carcinoid. Results in 98 patients. Cancer 2004; 101: 1987-93.

30. Hoefnagel CA. Metaiodobenzylguanidine and somatostatin in oncology: role in the management of neural crest tumors. Eur J Nuc Med 1994; 21: 561-81.

31. Mitry E, Baudin E, Ducreux M, et al. Treatment of poorly differentiated neuroendocrine tumours with etoposide and cisplatin. $\mathrm{Br}$ J Cancer 1999; 81: 1351-5.

32. Moertel CG, Kvols LK, O'Connell MJ, Rubin J. Treatment of neuroendocrine carcinoma with combined etoposide and cisplatin. Evidence of major therapeutic activity in the anaplastic variants of these neoplasms. Cancer 1991; 68: 227-32.

33. Fjällskog ML, Granberg DP, Welin SL, Eriksson C, Oberg KE, Janson ET, Eriksson BK. Treatment with cisplatin and etoposide in patients with neuroendocrine tumours. Cancer 2001; 92: 1101-7.

34. Bajetta E, Catena L, Procopio G, et al. Are capecitabine and oxaliplatin (Xelox) suitable treatments for progressing low-grade and highgrade neuroendocrine tumours? Cancer Chemother Pharmacol 2007; 59: 637-42.

35. Yao JC, Lombard-Bohas C, Baudin E, et al. Daily oral everolimus activity in patients with metastatic pancreatic neuroendocrine tumors after failure of cytotoxic chemotherapy: a phase II trial. J Clin Oncol 2010; 28: 69-76.

36. Yao JC, Phan AT, Chang DZ, et al. Efficacy of RAD001 (everolimus) and octreotide LAR in advanced low- to intermediate-grade neu roendocrine tumors: results of a phase II study. J Clin Oncol 2008; 26: 4311-8

37. O'Donnell A, Faivre S, Burris HA 3rd, et al. Phase I pharmacokinetic and pharmacodynamic study of the oral mammalian target of rapamycin inhibitor everolimus in patients with advanced solid tumors. J Clin Oncol 2008; 26: 1588-95.

38. von Wichert G, Jehle PM, Hoeflich A, et al. Insulin-like growth factor-l is an autocrine regulator of chromogranin A secretion and growth in human neuroendocrine tumor cells. Cancer Res 2000; 60: 4573-81.

39. Yao JC, Shah MH, Ito T, et al. Everolimus for advanced pancreatic neuroendocrine tumors. N Engl I Med 2011; 364: 514-23.

40. Zhang J, Jia Z, Li Q, et al. Elevated expression of vascular endothe lial growth factor correlates with increased progression-free survival among patients with low-grade neuroendocrine tumors. Cancer 2007; 109: 1478-86.

41. Arnold R, Chen YJ, Costa F, et al. ENETS Consensus Guidelines for the Standards of Care in Neuroendocrine Tumors: follow-up and documentation. Neuroendocrinology 2009; 90: 227-33.

42. Plöckinger U, Rindi G, Arnold R, et al. Guidelines for the diagnosis and treatment of neuroendocrine gastrointestinal tumours. A consensus statement on behalf of the European Neuroendocrine Tumour Society (ENETS). Neuroendocrinology 2004; 80: 394-424.

43. Nehar D, Lombard-Bohas C, Olivieri S, Claustrat B, Chayvialle JA, Penes MC, Sassolas G, Borson-Chazot F. Interest of chromogranin A for diagnosis and follow-up of endocrine tumours. Clin Endocrinol (Oxf) 2004; 60: 644-52.

44. Bolanowski M, Jarząb B, Handkiewicz-Junak D i wsp. Guzy neuroendokrynne jelita cienkiego i wyrostka robaczkowego (zasady postępowania rekomendowane przez Polską Sieć Guzów Neuroendokrynnych). Endokrynol Pol 2008; 59: 87-96.
45. Eriksson B, Klöppel G, Krenning E, et al. Consensus guidelines for the management of patients with digestive neuroendocrine tumors - well-differentiated jejunal-ileal tumor/carcinoma. Neuroendocrinology 2008; 87: 8-19.

46. O'Toole D, Grossman A, Gross D, et al. ENETS Consensus Guidelines for the Standards of Care in Neuroendocrine Tumors: biochemical markers. Neuroendocrinology 2009; 90: 194-202.

47. Sundin A, Vullierme MP, Kaltsas G, Plöckinger U. ENETS Consensus Guidelines for the Standards of Care in Neuroendocrine Tumors: radiological examinations. Neuroendocrinology 2009; 90: 167-83.

48. Kwekkeboom DJ, Krenning EP, Scheidhauer K, et al. ENETS Consensus Guidelines for the Standards of Care in Neuroendocrine Tumors: somatostatin receptor imaging with (111)In-pentetreotide. Neuroendocrinology 2009; 90: 184-9.

49. Plöckinger U, Couvelard A, Falconi M, et al. Consensus guidelines for the management of patients with digestive neuroendocrine tumours well-differentiated tumour/carcinoma of the appendix and goblet cell carcinoma. Neuroendocrinology 2008; 87: 20-30.

50. Ramage JK, Goretzki PE, Manfredi R, et al. Consensus guidelines for the management of patients with digestive neuroendocrine tumours: well-differentiated colon and rectum tumour/carcinoma. Neuroendocrinology 2008; 87: 31-9.

51. Van Gompel JJ, Sippel RS, Warner TF, Chen H. Gastrointestinal carcinoid tumors: factors that predict outcome. World J Surg 2004; 28: 387-92.

52. Kölby L, Bernhardt P, Swärd C, et al. Chromogranin A as a determinant of midgut carcinoid tumour volume. Regul Pept 2004; 120: 269-73.

53. Falconi M, Plockinger U, Kwekkeboom DJ, et al. Well-differentiated pancreatic nonfunctioning tumors/carcinoma. Neuroendocrinology 2006; 84: 196-211.

54. Nilsson O, Van Cutsem E, Delle Fave G, et al. Poorly differentiated carcinomas of the foregut. Neuroendocrinology 2006; 84: 212-5.

\section{Address for correspondence}

Paweł Gut MD, PhD

Department of Endocrinology and Metabolism

Poznan University of Medical Sciences

Przybyszewskiego 49

60-355 Poznan

tel. 607392922

e-mail: gutpj@poczta.onet.pl

Sumbitted: $\quad 23.08 .2012$

Accepted: $\quad 28.10 .2012$ 